\title{
Fatores Condicionantes de Suscetibilidade a Ocorrência de Deslizamentos de Terra nas Rodovias do Maciço de Baturité, Ceará.
}

\author{
Determinants factors Susceptibility to Landslides occurred Land in Highway Maciço de \\ Baturité, Ceará.
}

JUVENAL, P.H.S ${ }^{1}$; SANTOS, R.R ${ }^{2}$; OLIVEIRA, F.L.S ${ }^{3}$; SILVA, C.A ${ }^{4}{ }^{.}$ pedrojuvenal_2059@hotmail.com;

\begin{abstract}
Resumo
O presente artigo propõe analisar os fatores condicionantes de suscetibilidade que contribuem para agravar a vulnerabilidade das pessoas nas rodovias do Maciço de Baturité. Ocasionalmente no período chuvoso ocorrem deslizamentos de terra na área, principalmente devido aos cortes das encostas que bordeiam grande parte das vias, com ausência de contenção. Oferecendo risco aos moradores locais e aos transeuntes, tendo em vista que o Maciço de Baturité é uma importante área turística do Estado do Ceará. Além, disso no artigo foi analisado a disponibilidade de serviços e contingente para socorro e salvamento em caso de emergência na região. Apesar da pesquisa está em fase inicial, foi possível concluir que caso ocorra esses deslizamentos, que geralmente interrompe o tráfego nas rodovias e-dificultaria o trabalho do resgate de vítimas. Os resultados serão importantes para elaboração de possíveis planos de contingência de modo que contribua para a conscientização da população e alerte sobre os riscos de deslizamentos de terra as autoridades competentes.
\end{abstract}

Palavras-chave: Deslizamentos de terra, Maciço de Baturité, Rodovias.

\begin{abstract}
This article aims to analyze the susceptibility of conditioning factors that contribute to aggravate the vulnerability of people in the Baturité Massif highways. Occasionally occur in the rainy season landslides in the area, mainly due to cuts the slopes that bordeiam much of the way, with no restraint. Posing a risk to local residents and passers-by, given that the Maciço de Baturite is an important tourist area of Ceara. In addition, that the article was analyzed the availability of services and contingent for relief and rescue in case of emergency in the region. Although the research is at an early stage, it was concluded that in the event of these landslides, which usually interrupt the traffic on the roads and hinder the work of the rescue of victims. The results will be important for the development of possible plans of contingency in order to contribute to public awareness and alert about the risks of landslides competent authorities.
\end{abstract}

Keywords: Landslides, Maciço de Baturité, Highways.

\section{INTRODUÇÃ $\bar{O}$}

O nordeste brasileiro conta com diversas peculiaridades, desse modo não podemos dissociar o Nordeste de sua principal característica, o semiárido, esse segundo Ab’Sáber (1977) apresenta grande diversidade ambiental, além de complexa variedade de fatores naturais dispersos ao longo do semiárido, nesse ambiente ocorre o predomínio das superfícies sertanejas intermontanas quentes e secas, mal servidas por chuvas tropicais.

\footnotetext{
${ }^{1}$ Pedro Henrique da Silva Juvenal, Laboratório de Geoprocessamento e Estudos Aplicados - LabGeo, Universidade Estadual do Ceará-UECE, Fortaleza-CE, Brasil.

${ }^{2}$ Rafael Reis do Santos, Laboratório de Geoprocessamento e Estudos Aplicados - LabGeo, Universidade Estadual do Ceará UECE, Fortaleza-CE, Brasil.

${ }^{3}$ Francisca Leiliane Sousa de Oliveira, Doutoranda do Programa de Pós-Graduação em Geografia - ProPGeo/UECE, Laboratório de Geoprocessamento e Estudos Aplicados - LabGeo, Universidade Estadual do Ceará - UECE, Fortaleza-CE, Brasil.

4 Cristiano Alves da Silva, Doutorando, Programa de Pós-Graduação em Geologia, Universidade Federal do Ceará - UFC, Fortaleza-CE, Brasil.
} 
Desse modo o Nordeste é um território onde ocorrem longas estiagens e secas, expressas também na literatura brasileira como, por exemplo, no livro "O Quinze" (1930) de Rachel de Queiroz e "Vidas Secas" (1938) de Graciliano Ramos.

Entretanto, o Nordeste possui áreas de exceção, ainda segundo Ab’Sáber (2003), o interior da área nuclear do domínio das caatingas existem vários ambientes de exceção, como é o caso dos maciços úmidos e subúmidos. Essas paisagens de exceção são conhecidas como "brejos de altitude".

Nessa perspectiva o nordeste semiárido apresenta onze enclaves úmidos e subúmidos que se encontram distribuídos pelos Estados do Ceará, Rio Grande do Norte, Paraíba, Pernambuco, Alagoas e Bahia (Souza e Oliveira, 2006). No contexto cearense podemos citar Bastos (2012), que apresenta os relevos que explanam essas configurações naturais, são as serras ou maciços de Uruburetama, Aratanha, Maranguape, Meruoca e Baturité.

Referente ao Maciço de Baturité, objeto de estudo do presente trabalho, localiza-se no centro-norte do Ceará, é composta pelos municípios de Pacoti, Palmácia, Guaramiranga, Mulungu, Aratuba, Capistrano, Itapiúna, Baturité, Aracoiaba, Acarape, Redenção, Barreira e Ocara. Está situado a 90 (noventa) quilômetros de Fortaleza e tem como principais acessos, partindo de Fortaleza, a rodovia CE - 060, sentido Pacatuba-Baturité e a rodovia CE - 065, sentido MaranguapePalmácia, o local em questão abriga uma Área de Proteção Ambiental - APA, esta é a primeira e mais extensa criada pelo Governo do Estado do Ceará, instituída através do decreto estadual $\mathrm{N}^{\circ}$ 20.956, de 18 de setembro de 1990 alterado pelo decreto $\mathrm{N}^{\circ} 27.290$, de 15 de dezembro de 2003, abrange uma área de 32.690 hectares, na região serrana do Maciço de Baturité CEARÁ (2003).

Desse modo o Maciço de Baturité é o local com maior intensidade de precipitações do Estado segundo a Fundação Cearense de Meteorologia e Recursos Hídricos (FUNCEME), sendo assim, as ocorrências de deslizamentos de terra nas rodovias de acessos são recorrentes na região, portanto, dando ao relevo uma caracterização superficial bastante dinâmica.

Quanto aos movimentos de massa, Bastos (Op. cit), explana que dentre os processos modeladores do relevo da superfície terrestre destacam-se os movimentos de massa, que se caracterizam por uma significativa dissipação de energia, sendo responsáveis pelo deslocamento de material nas encostas de relevo, podendo ser esses eventos decorrentes de fatores naturais.

Nessa perspectiva o presente trabalho tem por objetivo identificar fatores condicionantes de suscetibilidade a ocorrência de deslizamentos de terra nas principais rodovias do maciço de Baturité, além de analisar a disponibilidade de serviços de Urgência/Emergência em caso de desastre. 


\section{METODOLOGIA}

Em síntese, a metodologia deste trabalho segue parâmetros de pesquisa descritivoexplicativo, que consiste em descrever características da população, de um fenômeno ou de uma experiência. Para a definição do objeto de estudo e seu recorte espacial, requereu-se uma abordagem com o objetivo de identificar os agentes que tornam suscetível a estrutura das rodovias de acesso ao Maciço de Baturité.

Referente aos procedimentos operacionais, incialmente foi levantando um acervo bibliográfico e geocartográfico, dados em fontes secundárias, levantamento de informações em atividades de campo e identificação dos trechos das rodovias. As etapas de trabalho descritas nesse artigo podem ser observadas no quadro 1 .

Quadro 1: Procedimentos operacionais e coleta de dados durante a pesquisa. Fonte: Autores (2016).

\begin{tabular}{|l|l|}
\hline Procedimentos operacionais e coleta de dados durante a pesquisa. \\
\hline 1. & $\begin{array}{l}\text { Material bibliográfico - pesquisa e análise de teses, artigos, matérias em } \\
\text { jornais, projetos, programas, entre outros textos disponíveis em sites; }\end{array}$ \\
\hline 2. & Material geocartográfico - pesquisa e análise; \\
\hline 3. & $\begin{array}{l}\text { Definição das rodovias e dos trechos a serem analisados - elaboração de } \\
\text { tabelas e mapas (localização e carta imagem); }\end{array}$ \\
\hline 4. & $\begin{array}{l}\text { Pesquisa e identificação de equipes de socorro e salvamento (Grupos de } \\
\text { Socorro e Urgência e o Núcleo de Busca e Salvamento) no Maciço de } \\
\text { Baturité; }\end{array}$ \\
\hline 5. & $\begin{array}{l}\text { Elaboração de ficha de campo: exposição das vertentes; qualidade da } \\
\text { pavimentação; existência de contenção; }\end{array}$ \\
\hline
\end{tabular}

Os trechos das rodovias analisadas nesse trabalho são:

- CE- 060/CE-356: Trecho Município de Baturité ao Município de Guaramiranga;

- CE-253: Trecho Distrito de Inhuporanga no Município de Caridade até o distrito Lagoa no município de Guaramiranga;

- CE-065: Trecho Município de Palmácea até o Município de Pacoti.

\subsection{Referencial Teórico}

O termo suscetibilidade apresenta diferentes maneiras de interpretação, desse modo, buscamos em Julião et. al (2009), a definição do termo suscetibilidade, como a incidência espacial do perigo, representando a propensão para uma determinada área ser afetada por um determinado perigo, em tempo indeterminado, sendo avaliada através dos fatores de predisposição para a 
ocorrência dos processos ou ações, não contemplando o seu período de retorno ou a probabilidade de ocorrência.

Para Cutter (1993 apud ALMEIDA, 2012), a vulnerabilidade caracteriza-se por ser a probabilidade ao qual um indivíduo ou grupo estão exposto ou afetados a um perigo, é a interação entre o ambiente físico, do risco, com a situação socioeconômica.

Conforme o Ministério da Saúde do Brasil por meio da portaria número 354 de março de 2014 define como emergência; a constatação médica de condições de agravo a saúde que impliquem sofrimento intenso ou risco iminente de morte, exigindo, portanto, tratamento médico imediato. E urgência a ocorrência imprevista de agravo a saúde como ou sem risco potencial a vida, cujo portador necessita de assistência médica imediata.

O termo genérico escorregamentos ou deslizamentos engloba uma variedade de tipos de movimentos de massa de solos, rochas ou detritos, gerados pela ação da gravidade, em terrenos inclinados, tendo como fator deflagrador principal a infiltração de água, principalmente das chuvas. (IPT, 2007). No período chuvoso ocorrem deslizamentos de terra na área no maciço de Baturité, principalmente devido aos cortes das encostas que bordeiam grande parte das vias, com ausência de contenção.

A tese intitulada "Movimentos de massa no maciço de Baturité (CE) e contribuições para estratégias de planejamento ambiental" apresentada por Bastos (2012) é uma das principais referências para o presente estudo. Para o autor, a distribuição espacial das rodovias no maciço de Baturité e principalmente os cortes feitos para a construção de estradas, se caracterizam como o principal agente desencadeador dos movimentos de massa atuais e em grande parte dos registros de deslizamentos ocorreram nesses locais.

Quanto à ocupação das encostas e contas associada aos movimentos de massa, o autor afirma:

A ocupação de encostas a partir de atividades agrícolas, expansão urbana e construção de estradas tem sido responsável pela instabilização de áreas já suscetíveis a movimentos de massa e isso se deve tanto pelos desmatamentos associados, como pela modificação na morfologia das vertentes (Bastos, 2012, p. 60).

De acordo com Highland e Peter (2008), deslizamento é usado para descrever o movimento de descida do solo, de rochas e material orgânico, sob o efeito da gravidade, e também a formação geológica resultante de tal movimento.

\section{RESULTADOS E DISCUSSÃO}

A malha rodoviária do Maciço de Baturité é composta por rodovias de jurisdição federal e estadual, como, mostra a tabela elaborada pelo Departamento de Estradas e Rodovias/CE - 
DER/CE (vide figura 1), é utilizada também pelo Ministério do Desenvolvimento Agrário - MDA, em seu Plano Territorial de Desenvolvimento Rural Sustentável: Território Cidadania Maciço do Baturité.

\begin{tabular}{|c|c|c|c|c|}
\hline $\begin{array}{l}\text { MICRO } \\
\text { TERRITÓRIOS }\end{array}$ & MUNICIPIOS & $\begin{array}{l}\text { Área } \\
\left(\mathrm{km}^{2}\right)\end{array}$ & Vias de Acesso & $\begin{array}{r}\text { Distancia de } \\
\text { Fortaleza }(\mathrm{km})\end{array}$ \\
\hline \multirow{5}{*}{$\begin{array}{l}\text { MICRO } \\
\text { TERRITÓRIOI }\end{array}$} & Aratuba & 157,5 & CE-065 & 128 \\
\hline & Guaramiranga & 107,6 & CE-065 & 102 \\
\hline & Mulungu & 103,8 & CE-065 & 110 \\
\hline & Pacoti & 94,5 & CE-065 & 95 \\
\hline & Palmácia & 150,8 & CE-065 & 73 \\
\hline \multirow{6}{*}{$\begin{array}{l}\text { MICRO } \\
\text { TERRITÓRIO ॥ }\end{array}$} & Acarape & 182,6 & CE-060 & 61 \\
\hline & Aracoiaba & 628,1 & CE-060 & 83 \\
\hline & Baturité & 347,3 & CE-060/ CE-356 & 93 \\
\hline & Capistrano & 186,9 & CE-060 & 110,5 \\
\hline & Itapiúna & 592,9 & CE-060 & 110 \\
\hline & Redenção & 240,7 & CE-060 & 63 \\
\hline \multirow[b]{2}{*}{$\begin{array}{l}\text { MICRO } \\
\text { TERRITÓRIO III }\end{array}$} & Barreira & 228,3 & CE-060/ CE-354 & 75,5 \\
\hline & Ocara & 775,2 & $\begin{array}{l}\text { BR-116/CE- } \\
359 / C E-257\end{array}$ & 97,1 \\
\hline
\end{tabular}

Figura 1: Vias de acesso aos municípios e distância a Fortaleza. Fonte: DER (2009).

Como pode ser observado, as rodovias CE 060 e CE 065, possuem papel fundamental no sistema viário do Maciço, constituem as principais vias de acesso entre o Maciço e Fortaleza, capital do Estado.

No plano, Plano Territorial de Desenvolvimento Rural Sustentável: Território Cidadania Maciço do Baturité, se destaca que a mobilidade de acesso entre a maioria dos municípios do Maciço é possível, unicamente, através do transporte rodoviário. As rodovias estaduais CE-060, CE-065 e CE-356, protagonizam as principais ligações entre os mesmos, BRASIL (2010).

O MDA faz uma análise das condições estruturais da infraestrutura das rodovias, onde podemos destacar:

- CE-065: se estende por cerca de 128 quilômetros, pelos municípios de Aratuba / Mulungu / Guaramiranga / Pacoti / Palmácia, o pavimento encontra-se em boas condições de conservação, mas com dimensões de acostamento inadequadas. Já no trecho Palmácia / Ladeira Grande, a CE-065 apresenta estado muito precário, com a pavimentação mal conservada, neste trecho a pista possui seção reduzida, além de ser desprovida de uma sinalização eficiente, o que a torna uma rodovia perigosa para o tráfego;

- CE-060 no trecho de Fortaleza / Aracoiaba, conta com pavimentação em ótimas condições de conservação e excelente sinalização horizontal e vertical, em sua totalidade a CE possui cerca de 540 quilômetros de extensão se estendendo de Fortaleza até o município de Jardim, no sul cearense, (BRASIL, Op. Cit.).

Vale ressaltar que os trechos das rodovias analisadas nesse trabalho, foram identificados e classificados a partir da ocorrência de deslizamentos passados e tendo em vista que o Maciço de 
Baturité é uma importante área turística do Estado do Ceará, com fluxo constante de moradores locais além de transeuntes.

Os trechos em destaque são: CE- 060/CE-356: Trecho Município de Baturité ao Município de Guaramiranga; CE-253: Trecho Distrito de Inhuporanga no Município de Caridade até o distrito Lagoa no município de Guaramiranga e CE-065: Trecho Município de Palmácea até o Município de Pacoti. A partir, dessas informações foi elaborada a figura $2 .^{5}$

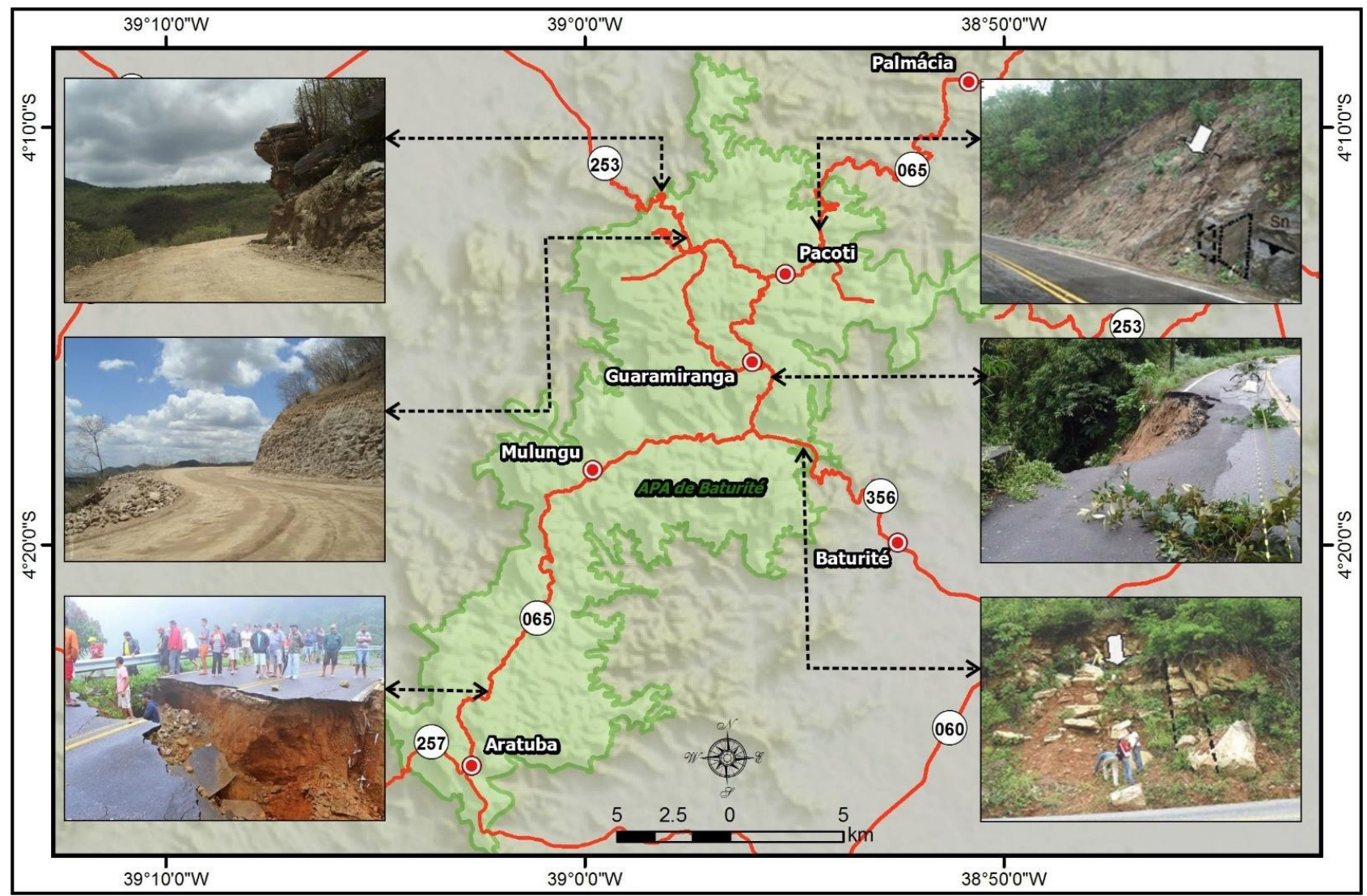

Figura 2: Mapa das principais rodovias do maciço de Baturité, com destaque para características gerais da paisagem. Fonte: Elaborado pelos autores (2016).

Assim, as rodovias do Maciço em sua estrutura de modo geral apresentam um bom estado de conservação, por essa razão, o risco de deslizamento é totalmente desconsiderado pelas autoridades e responsável pela construção e manutenção das vias comentadas anteriormente, pois, nas visitas de campo se observou a falta de medidas preventivas e ausência total de qualquer tipo de obra de engenharia voltada para a contenção de possíveis deslizamentos.

A falta de prevenção, tornam as vias suscetíveis a casos de deslizamentos de terra, a partir desses elementos surge a necessidade de incluir o termo risco na presente pesquisa. Zanella e

\footnotetext{
5 As figuras apresentadas no mapa de rodovias do Maciço de Baturité são encontradas respectivamente: http://www.panoramio.com (Fig.1e2); http://www.aratubaonline.com/2014/05/chuva-abre-cratera-e-interdita-ce257.html(Fig.3); BATISTA, 2014 (Fig. 4 e 6, página 80);http://tvmacicoasuatv.blogspot.com.br/2015/07/deslizamentosna-serra-de-guaramiranga.html (Fig. 5); Acesso em 12 de agosto de 2016.
} 
Olímpio, afirmam que a "[...] noção de risco é empregada em uma situação de futuro incerto e de probabilidade de que um evento danoso atue sobre uma população e seus bens matérias e imateriais reconhecidamente vulnerável, causando danos e prejuízos [...]" (ZANELLA; OLÍMPIO, p. 117, 2014). Outra atividade comum foi encontrar cortes em encostas próximos a rodovias, para a construção de novos acessos. Normalmente, a encosta é deixada exposta a poucos metros da via, como na figura 03.

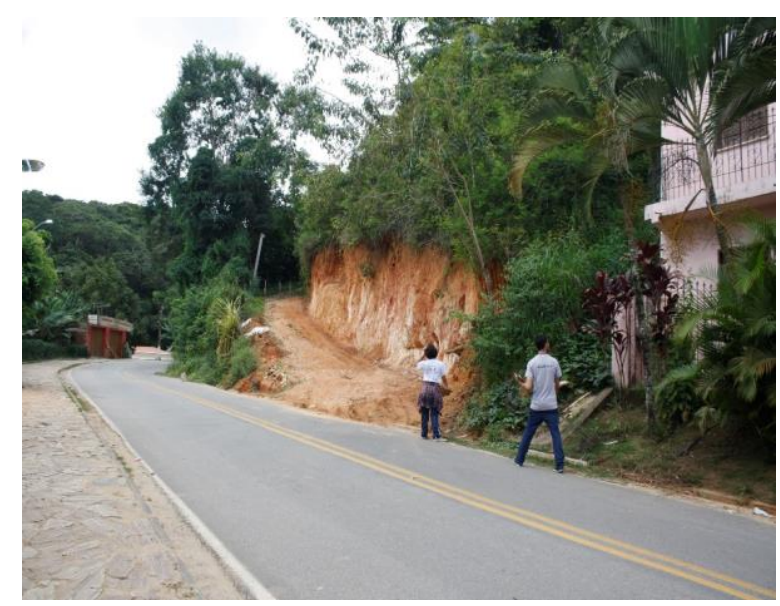

Figura 03: Corte em vertente para construção de acesso a residências de veraneio. Município de Pacoti, na CE-065.

Fonte: Autores, (2016).

As medidas de prevenção, tomam caráter emergencial, pois durante os levantamentos de dados, os eventos são periodicamente noticiados pelos jornais e meios de comunicação da região, a exemplo a matéria do jornal eletrônico ${ }^{6}$, G1 Ceará com uma matéria “Após chuva e buraco, acesso a Guaramiranga segue em meia pista”, o jornal segue noticiando que as chuvas fortes do fim de semana abriram uma cratera próxima a Guaramiranga, no Maciço de Baturité, interditando parte da rodovia. Na Figura 04, demonstra perfeitamente um exemplo de deslizamento em rodovias que causam prejuízos à população.

\footnotetext{
${ }^{6}$ Notícia originada do Portal Eletrônico G1 - Ceará: “Após chuva e buraco, acesso a Guaramiranga segue em meia pista”. Disponível em: http://g1.globo.com/ceara/noticia/2015/07/apos-chuva-e-buraco-acesso-guaramiranga-segue-emmeia-pista.html, acesso em 13 de agosto de 2016.
} 


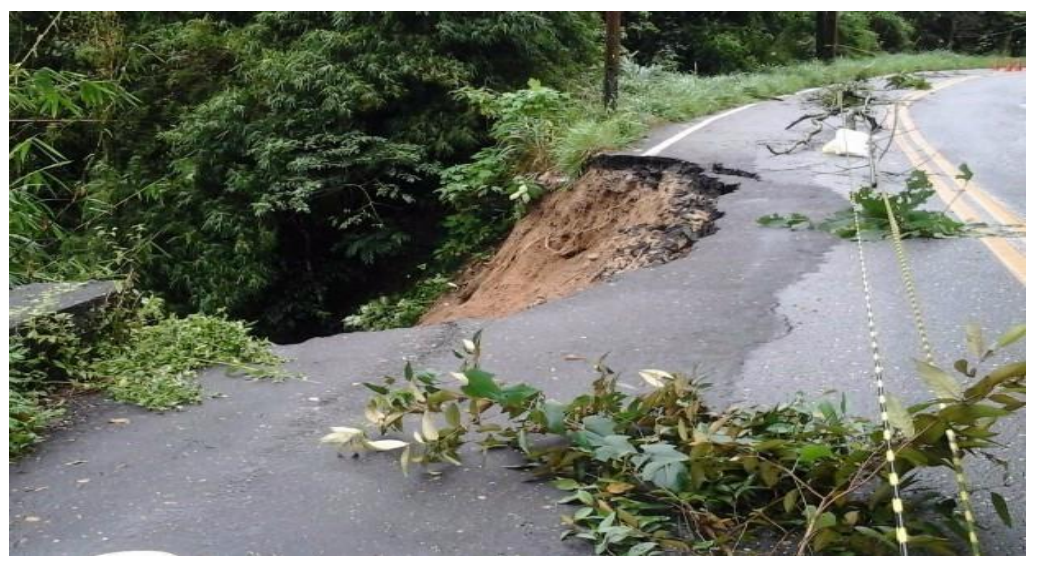

Figura 04: Deslizamento na CE-356, próximo ao município de Guaramiranga. Fonte: G1/PRE/Divulgação.

Considerando as distâncias, a média de uma cidade a outra no Maciço é cerca de 39 (trinta e nove) quilômetros, o que é necessário se levar em conta em caso de queda em alguma encosta, pois o tempo que se levaria para que uma equipe de socorro e salvamento para percorrer esta distância mínima poderia dificultar o resgate em caso de feridos.

Outro problema grave é a disponibilidade de contingente, viaturas e destacamentos, pois no Maciço há apenas um destacamento dos bombeiros situado na cidade de Guaramiranga, porém somente em Fortaleza, a aproximadamente 90 (noventa) quilômetros de distância, possui os seguintes destacamentos, Grupo de Socorro e Urgência e o Núcleo de Busca e Salvamento, que são unidades adequadas para a ação em caso de emergência. Mais um agravante é a comunicação com o destacamento, pois os contatos que são disponibilizados no site da Secretaria de Segurança Pública e Defesa Social não são eficazes para a comunicação.

Segundo Paiva (2011) poderiam ser realizadas algumas obras de contenção para evitar que ocorressem novos deslizamentos, que atendam as expectativas no custo benefício. São obras de estabilização, medidas que evitam grandes movimentações de solo, consiste na instalação de drenagem especifica acompanhada de uma proteção superficial, com materiais naturais e artificiais. Este tipo de estrutura tem o objetivo de evitar a proliferação de processos erosivos e a infiltração de água.

\section{CONSIDERAÇÕES FINAIS}

Foi possível identificar que as pessoas que utilizam as rodovias do Maciço de Baturité, estão expostas a deslizamentos de terra e/ou quedas de bloco, em vários trechos das rodovias, em diferentes níveis de risco e vulnerabilidade. 
Quanto aos fatores condicionantes de suscetibilidade a ocorrência desses eventos (deslizamentos de terra e/ou quedas de bloco) estão principalmente associados aos cortes nas encostas, a declividade, a supressão de vegetação e a falta de contenção.

Caso ocorra esse tipo de evento, são previstos danos sociais, econômicos e ambientais, desse modo faz-se necessário propor medidas aos gestores públicos para intervir nas estruturas das rodovias, principalmente buscando formas de contenção das encostas, com a instalação e melhoria da drenagem. Além disso, há necessidade de investimentos em medidas não estruturais, como a construção de políticas públicas de gestão de risco de maneira integrada entre os municípios do Maciço de Baturité e o estado. Vale salientar, que a pesquisa se encontra em fase inicial e tem como perspectiva a elaboração de atividades aprofundadas na temática. Dentre as atividades previstas com a continuação da pesquisa estão:

- Localização e identificação georreferenciada dos pontos críticos nas rodovias analisadas;

- Propor medidas específicas de prevenção a ocorrências de deslizamentos de terra;

- Estimativa da população direta e indiretamente afetada caso ocorra deslizamentos;

- Propor ações de segurança viária (obras estruturais - contenção de encostas);

\section{REFERÊNCIAS}

AB’ SÁBER, A. N. A Problematização da Desertificação e da Savanização no Brasil. São Paulo: USP. Instituto de Geografia. Boletim Paulista de Geografia, n.3, 1977.

Os Domínios de Natureza no Brasil: Potencialidades Paisagísticas, 3 ed. Ateliê Editorial, São Paulo. 2003

ALMEIDA, L. Q. Riscos Ambientais e Vulnerabilidades nas Cidades Brasileiras: conceitos, metodologias e aplicações. São Paulo: Cultura Acadêmica, 2012.

BARROS, J. L. A. A. Riscos Naturais e Tecnológicos com Expressão no Concelho de Lamega: Contributo para o Ordenamento e Gestão de Emergência Municipal. Dissertação (Mestrado em Dinâmicas Sociais, Riscos Naturais e Tecnológicos), Coimbra, Universidade de Coimbra. 2010. 105 p.

BASTOS, F.H. Movimentos de massa no maciço de Baturité (CE) e contribuições para estratégias de planejamento ambiental. Tese (Doutorado em Geografia). Fortaleza, Universidade Federal do Ceará. 2012. 257 p.

BATISTA, C. T.; VERÍSSIMO, C. U. V.; AMARAL, W. S. Levantamento de feições estruturais lineares a partir de sensoriamento remoto - uma contribuição para o mapeamento geotécnico na Serra de Baturité, Ceará. Geol. USP, Sér. cient., jun. 2014, vol.14, no.2, p.76-82. 
BRASIL. Ministério do Desenvolvimento Agrário. Plano Territorial de Desenvolvimento Rural Sustentável: Território Cidadania Maciço do Baturité - MDA/SDT/CONSAD Fortaleza: Instituto Agropolos do Ceará, 2010.

. Ministério da Saúde, Portaria no 354, de 10 de Março de 2014.

CEARÁ. Secretaria da Segurança Pública e Defesa Social, disponível em: http://www.defesacivil.ce.gov.br/index.php?option=com_content\&view=article\&id=72:fonesunidoperinterior \&catid=14:lista-de-noticias\&Itemid=81, acesso em 12 de agosto de 2016. HIGHLAND, L.M. BOBROWSKY, P. The landslide handbook - A guide to understanding landslides: Reston, Virginia, U.S. Geological Survey Circular. 2008, 1325, p.6 SÃO PAULO. Instituto de Pesquisas Tecnológicas - IPT. Mapeamento de Riscos em Encostas e Margem de Rios / Celso Santos Carvalho (Org.) - Brasília: Ministério das Cidades; Instituto de Pesquisas Tecnológicas - IPT, 2007.

SOUZA, M.J.N.; OLIVEIRA, V.P.V. Os enclaves úmidos e subúmidos do semiárido do Nordeste brasileiro. Mercator, n. 5, v.9, 2006, p. 85-102.

ZANELLA, M. E. OLÍMPIO, J. L. Impactos pluviais, risco e vulnerabilidades em Fortaleza-CE. In: Mendonça, F. A (Org.). Riscos Climáticos: vulnerabilidades e resiliência associados. Jundiaí: Paco Editorial. 2014. p. 115-136.

\section{AGRADECIMENTOS}

Agradecemos a bolsa de estudos recebida da Pró - Reitoria de Políticas Estudantis - PRAE, através do Programa de Bolsas de Estudos e Permanência Universitária - PBEPU.

Ao Laboratório de Geoprocessamento e Estudos Aplicados - LabGeo e ao Grupo de Pesquisa GeoDesastre, Universidade Estadual do Ceará - UECE, Fortaleza/ CE, Brasil.

Recebido em: 14/08/2016

Aceito para publicação em: 01/10/2016 